\title{
CONCEPÇÕES E PRÁTICAS PEDAGÓGICAS E O ENSINO DA MATEMÁTICA NA EDUCAÇÃO INFANTIL
}

\author{
PEDAGOGICAL CONCEPTIONS AND PRACTICES AND THE \\ TEACHING OF MATHEMATICS IN CHILDREN EDUCATION
}

\author{
Amanda Popiolski ${ }^{1}$ \\ Thais Iane Dos Santos ${ }^{2}$ \\ Ana Paula Rohrbek Chiarello ${ }^{3}$
}

\begin{abstract}
Resumo
Este artigo tem como objetivo analisar a importância das concepções e práticas pedagógicas no Ensino da Matemática na Educação Infantil. De forma mais específica, discute o potencial integrador da criança em uma abordagem piagetiana, articulando a matemática à ludicidade. O estudo, de base qualitativa, é resultado de uma pesquisa bibliográfica. Como delimitação metodológica, foi realizado um levantamento, a partir de artigos publicados no periódico SBEM (Educação Matemática em Revista), com o propósito de analisar como se ensina e quais atividades matemáticas vêm sendo utilizadas como recursos pedagógicos na Educação Infantil. Concluímos, com a análise, que, para assegurar situações de aprendizagem significativas nessa etapa da escolarização, é preciso priorizar os conhecimentos prévios da criança, relacionando a matemática às demais linguagens, nas quais o lúdico está presente.
\end{abstract}

Palavras-Chave: Educação Infantil; Educação Matemática; Práticas Pedagógicas.

\begin{abstract}
This article aims to analyze the importance of pedagogical conceptions and practices in the teaching of mathematics in early childhood education. More specifically, it discusses the integrative potential of the child in a Piagetian approach, linking mathematics to playfulness. The study is qualitative and results from a bibliographical research conducted from articles published in the journal Sbem (Mathematical Education in Review). The purpose of the research was to analyze how it is taught and which mathematical activities have been used as pedagogical resources in early childhood education. It was
\end{abstract}

1 Graduada em Pedagogia pela UFFS. Professora da rede Particular de Ensino do município de ChapecóSC (Logosófico). E-mail: amanda_popiolski@ hotmail.com

2 Graduada em Pedagogia pela UFFS. Professora da rede Municipal de Chapecó-SC. E-mail: thaiis.iane@hotmail.com

3 Mestre em Educação (Educação Financeira). Professora conteudista UCEFF. E-mail: anapaula.rc@unochapeco.edu.br 
concluded with the analysis that to ensure significant learning situations in this stage of schooling, it is necessary to prioritize the child's prior knowledge, relating mathematics to other languages in which the ludic is present.

Keywords: Early Childhood Education. Mathematical Education. Pedagogical Practices.

\section{Introdução}

O Ensino da Matemática na Educação Infantil precisa estar focado na construção do conhecimento elaborado pela própria criança, em uma fase em que a curiosidade está muito presente. $\mathrm{O}$ professor se destaca como mediador desse processo, permitindo a ela conhecer suas próprias especificidades. Diante disso, o presente artigo tem como temática as concepções e práticas pedagógicas, com base no seguinte problema: como se ensina matemática na Educação Infantil? Tal problemática possui relevância, considerando-se ser a matemática fundamental para o desenvolvimento intelectual das crianças, visto que potencializa o que trazem de seu cotidiano, permitindo a articulação entre os conhecimentos prévios e os saberes científicos, através das atividades pedagógicas proposta pelos professores.

O trabalho está organizado em duas etapas. A primeira, "Os Caminhos da Pesquisa”, estrutura e apresenta os métodos utilizados no Ensino de Matemática, a partir de artigos publicados na revista SBEM (Educação Matemática em Revista), os quais abordam atividades voltadas para a Educação Infantil. Na segunda, "Do contexto aos resultados", apresentamos a análise dos artigos selecionados. A análise foi pensada a partir de três categorias: (i) Potencial Integrador; (ii) Ludicidade; e (iii) Práticas Pedagógicas, que emergiram da leitura dos textos. A primeira subseção, "O Ensino da Matemática na Educação Infantil: à luz dos pressupostos Piagetianos", aborda as contribuições dessa teoria ao Ensino da Matemática na Educação Infantil. A segunda, "A Ludicidade e o Ensino da Matemática", trata da importância de uma ação pedagógica envolvendo propostas lúdicas de maneira a possibilitar a construção de novos conhecimentos matemáticos através da articulação da teoria à prática, propiciando seu desenvolvimento integral. A terceira subseção, "Práticas Pedagógicas e o Ensino da Matemática", aborda a importância do Ensino da Matemática na Educação Infantil, evidenciando que as atividades pedagógicas devem possuir como foco a 
criança, abrangendo e percebendo a relevância de suas experiências e conhecimentos do mundo matemático, adquiridos antes do ingresso nos Centros de Educação Infantil.

\section{DO CONTEXTO DA PESQUISA AOS PROCEDIMENTOS METODOLÓGICOS}

Pensar em matemática na Educação Infantil nos parece uma proposta inovadora, dados os poucos estudos sobre tema e a importância desta para o desenvolvimento da potencialidade, do raciocínio lógico e da criatividade das crianças. Diante disto, propomo-nos a analisar concepções e práticas pedagógicas no Ensino da Matemática na Educação Infantil, à luz dos pressupostos construídos por Piaget.

Trata-se da socialização de uma pesquisa bibliográfica de base qualitativa. A metodologia para a realização deste estudo foi construída a partir de um levantamento de artigos publicados na Revista Sbem (Educação Matemática em Revista), com o propósito de analisar algumas atividades matemáticas lúdicas que vêm sendo utilizadas como recursos pedagógicos no contexto da Educação Infantil. Durante a análise, buscamos nos apoiar na abordagem piagetiana e nos pressupostos da Educação Matemática.

Os resultados da pesquisa serão apresentados por categorias, as quais, segundo Minayo (2004), são empregadas para estabelecer classificações, agrupando elementos, ideias e expressões em torno de um conceito. O material constitui-se de textos transcritos e organizados a partir da leitura dos 10 artigos que contemplaram a temática "Matemática na Educação Infantil"

A pesquisa foi desenvolvida em duas etapas: a primeira fase foi exploratória, pois teve por objetivo levar as pesquisadoras a lerem e conhecerem o que os artigos traziam sobre materiais matemáticos para a Educação Infantil; a segunda fase foi de "garimpo" e de aprofundamento, já que, dos 10 artigos lidos no primeiro momento, somente quatro apresentaram proposições de atividades para a Educação Infantil e, por isso, foram selecionados. A segunda etapa, então, foi dedicada à análise dos desses quatro textos. 


\section{OS CAMINHOS DA PESQUISA}

A análise, como já salientamos, foi pensada à luz dos pressupostos piagetianos. Dessa forma, foram definidas três categorias: (i) Potencial Integrador; (ii) Ludicidade e (iii) Práticas Pedagógicas. O recorte, apresentado a seguir, emerge da análise dos quatro artigos selecionados.

O artigo 1, "Vamos ao bosque? Problematizações e tratamento da informação na Educação Infantill", de Almeida, Fernandes e Megid (2017), traz discussões sobre a importância de os professores proporcionarem atividades envolvendo a estatística e a probabilidade com crianças da Educação Infantil e Anos Iniciais. No artigo 2, "Entre caixas, bolas e bambolês: a orientação espacial na Educação Infantil”, de Zogaib e Santos-Wagner (2017), as autoras trazem uma releitura de dados produzidos em experimento de ensino sobre senso espacial na Educação Infantil. No artigo 3, “Educação Infantil e a Matemática na Alimentação Saudável”, de Carniel et al. (2016), destacam-se as atividades feitas com uma turma de pré-escolar, com a qual foram trabalhados conceitos matemáticos interligados a outros projetos desenvolvidos com a turma. O artigo 4, "Qual Matemática para Crianças tão pequenas? Explorando as noções de Espaço com crianças de 1 a 3 anos", de Pellatieri (2010), relata uma atividade de exploração com bolas e caixas de diferentes tamanhos e problematiza as ações das crianças, sendo que toda a situação é videogravada. A atividade é voltada a uma faixa etária em que o Ensino de matemática, via de regra, é considerado uma tarefa impossível.

Optamos por construir a análise a partir de frames ${ }^{4}$. Dessa forma, visamos estabelecer uma relação entre a questão de pesquisa e os objetivos supracitados.

\section{DO CONTEXTO AOS RESULTADOS}

\subsection{O ENSINO DA MATEMÁTICA NA EDUCAÇÃO INFANTIL: À LUZ DOS PRESSUPOSTOS PIAGETIANOS}

4 O termo Frames é utilizado por Skovsmose (1999) para nominar comentários intercalados ao texto. Neste caso, chamaremos de frames as partes do texto trazidas pelos artigos. 
O pensamento de Piaget (1973) sobre a construção do conhecimento contrapõe tanto a corrente apriorista ou racionalista (inatista) quanto a empirista (sensorial), pois, para o autor, essa construção se estabelece na interação entre o raciocínio e a experiência sensorial. Nessa perspectiva teórica, o conhecimento, especialmente a capacidade de raciocinar logicamente, é construído por meio da interação/reflexão, na qual o sujeito opera sobre o objeto, buscando assim compreender sua experiência.

Logo, para Piaget (1973), o conhecimento é resultado da adaptação do sujeito ao meio, uma vez que vai se construindo pela ação da criança diante de situações que provocam desequilíbrios, ou melhor, quando os conhecimentos que o aluno possui não são suficientes para resolver algum problema. Como consequência, todo conhecimento novo é construído partindo dos conhecimentos anteriores que vão sendo modificados.

\footnotetext{
O conhecimento não procede, em suas origens, nem de um sujeito consciente de si mesmo nem de objetos já constituídos (do ponto de vista do sujeito) que a ele se imporiam. $\mathrm{O}$ conhecimento resultaria de interações que se produzem a meio caminho entre os dois, dependendo, portanto, dos dois ao mesmo tempo, mas em decorrência de uma indiferenciação completa e não de intercâmbio entre formas distintas. (PIAGET, 1973, p. 14).
}

Piaget (1973) compreende que o conhecimento é o resultado da construção que ocorre por meio da interação do sujeito com a realidade, sendo fundamental que as atividades propostas na Educação Infantil sejam planejadas, tendo como ponto de partida os conhecimentos prévios das crianças e possibilitando que elas os construam e ampliem de maneira significativa. Feito isso, há uma contribuição para o desenvolvimento integral das capacidades, competências e habilidades do ser humano.

De acordo com o artigo 1, constatamos que as autoras compreendem que

\footnotetext{
A finalidade da Educação Infantil não consiste em preparar para o Ensino Fundamental ou acelerar a apresentação de conteúdos, mas em ampliar o desenvolvimento das crianças. E, para que isso ocorra, é fundamental considerar as possibilidades da criança, seus interesses, sua curiosidade, lembrando que ela não apenas se prepara para a vida, mas já a vive. Nesse sentido, é essencial que as atividades propostas envolvam o universo infantil e propiciem discussões, ações e reflexões para a solução de problemas relevantes para a classe ou provocadas pelo professor. (ALMEIDA; FERNANDES; MEGID, 2017, p. 99. Artigo 1).
} 
Essa perspectiva vai ao encontro do pensamento de Goulart (1996), em seu estudo sobre Piaget. Nas palavras do autor, "uma aprendizagem compreensiva requer que o professor conheça o processo de pensamento do aprendiz, apresente problemas que lhe pareçam interessantes e para os quais ele possa oferecer resposta." (GOULART, 1996, p. 35). Dessa forma, oportunizar que a criança conviva em um espaço com diferentes materiais e situações proporciona que ela organize, elabore e construa novos conhecimentos, sendo que esses serão aprimorados com o tempo e com a mediação da professora. A atividade relatada no artigo 1 possui como ponto de partida o conhecimento prévio trazido à sala de aula, como podemos observar no frame a seguir:

\footnotetext{
Os momentos de discussão possibilitaram que as crianças argumentassem sobre suas ideias e justificativas a respeito de animais possíveis e impossíveis de serem encontrados em um bosque aberto à visitação pública.

M.L- Vai ter girafa. Ela é minha favorita.

L- Não vai ter girafa, ela não mora no bosque, ela mora na floresta. (ALMEIDA; FERNANDES; MEGID, 2017, p.101. Artigo 1).
}

Percebemos que, durante a atividade descrita, a professora possibilitou $\mathrm{o}$ contato com a estatística e com a probabilidade, proporcionando às crianças: momentos de listagem de hipóteses, ou seja, intuir acerca de quais animais poderiam ser encontrados no bosque; exposição e argumentação sobre os animais que seriam possíveis e impossíveis de encontrar no bosque; enfrentamento das hipóteses com as informações presentes; observação dos animais no bosque; ordenação das informações através da lista com nomes dos animais encontrados; tratamento de dados - produção do gráfico dos animais preferidos pela turma; e leitura e interpretação do gráfico, a partir da indagação proposta pela professora.

Encontramos, nos artigos 2 e 4, atividades que potencializam a construção de conceitos espaciais, tendo em vista o desenvolvimento de noções espaciais desde muito cedo. Por exemplo quando a curiosidade em relação ao espaço que está ao seu redor e com ele interagem, tentando pegar um objeto, engatinhando, rolando, empurrando.

Observamos, no frame abaixo, as potencialidades da atividade de circuito, descritas por Zogaib e Santos-Wagner (2017):

Ao analisarmos as potencialidades dessa atividade para o desenvolvimento do senso espacial, pensamos ser uma oportunidade para construir conceitos elementares de orientação espacial. A tarefa possibilita o trabalho com ideias sobre direção, localização e navegação: direita, esquerda, ir e voltar, dentro e fora etc., utilizando o próprio corpo da criança como referência para a locomoção. (ZOGAIB; SANTOS-WAGNER, 2017, p. 55. Artigo 2). 
Para a análise da proposta é preciso considerar o que diz Piaget (1970, p.100), para quem:

[...] é preciso que os objetos submetidos a deslocamento sejam considerados como coisas que se movem em relação recíproca ou em relação a certos pontos de referência; portanto, é imprescindível que se estabeleça entre eles um conjunto de relações espaciais. [Além disso] é preciso que o próprio sujeito se conceba como um objeto entre os demais elementos em jogo e represente os seus próprios deslocamentos como relativos aos das outras coisas.

Nesse sentido, apesar de um dos pontos destacados pelas autoras, inicialmente, ser a importância de se observar e considerar os conhecimentos prévios das crianças referentes ao senso espacial, não foi possível perceber, na descrição da atividade, a realização dessa estratégia.. Isso poderia acontecer através de uma roda de conversa, por meio de perguntas, ou de alguma brincadeira. Dessa forma, no contexto do construtivismo piagetiano, Carvalho et al. (2007, p.14) esclarecem que,

[...] os alunos trazem para a sala de aula conhecimentos já construídos, com os quais ouvem e interpretam o que falamos. Esses conhecimentos foram construídos durante sua vida através de interações com o meio físico e social e na procura de explicações do mundo.

Por isso, é fundamental que o professor planeje atividades que visem fazer com que as crianças passem de uma experimentação espontânea para um fazer científico, em que elas t pelas suas ideias, possam trocá-las e debatê-las.

O artigo 4 apresenta outra possibilidade para se trabalhar com os conceitos espaciais:

\begin{abstract}
A atividade consiste em solicitar às crianças que brinquem de colocar e tirar as bolas das caixas; entrar e sair das caixas; observar o que cabe e o que não cabe dentro de cada recipiente. O professor orienta a atividade sempre questionando e direcionando o olhar da criança. Pode-se perguntar: Quantas bolas cabem na caixa? Cabe mais? Você cabe na caixa? Em qual caixa cabem mais bolas? Os conteúdos matemáticos possíveis de serem explorados nessa atividade dizem respeito: às noções de espaço, formas e propriedades; às noções de dentro/fora, mais/menos; à classificação e à quantificação. (PELLATIERI, 2010, p. 28. Artigo 4).
\end{abstract}

Percebemos, na descrição, como a mediação da professora foi importante, estimulando as crianças a buscarem soluções para as situações-problema criadas durante a brincadeira, possibilitando que testassem suas hipóteses. Além dos contextos contemplados no artigo, podemos pensar a matemática aliada a outros projetos trabalhados na escola, conforme proposto pelo artigo 3 .

Em relação ao elemento água, fizemos uma conversa com a turma, questionando onde encontramos água e cada um opinou conforme pensava. 
Entre as respostas, surgiram às frutas e, com isso, desenvolvemos uma pesquisa sobre a quantidade de água existente nelas e, com o resultado, montamos um gráfico. [...] Além de estimular uma alimentação saudável, procuramos desenvolver propostas que contemplassem a construção de conceitos por meio da confecção de jogos como: do dominó, memória, quebra-cabeça, Sudoku, entre outros. Registros de receitas colocadas em prática e exploradas de diversas formas, como no preparo e na degustação. (CARNIEL et al., 2016, p. 44. Artigo 3).

O tema água permite um trabalho com a matemática de maneira interdisciplinar, utilizando recursos lúdicos e conteúdos ligados à realidade das crianças, como os relacionados à alimentação saudável, expandindo o conhecimento sobre o tema estudado e articulando os conhecimentos em diversas linguagens. Podemos observar, no frame, que a professora busca, através de perguntas, possibilitar que as crianças pensem, questionem, pesquisem, reflitam e sanem suas dúvidas. Dessa forma, evidencia-se o desenvolvimento do que propõe Smolle (2000, p.136), para quem:

O trabalho do professor não consiste em resolver problemas e tomar decisões sozinho. Ele anima e mantém as redes de conversas e coordena ações. Sobretudo, ele tenta discernir, durante as atividades, as novas possibilidades que poderiam abrir-se à comunidade da classe, orientando e selecionando aquelas que não ponham em risco algumas de suas finalidades mais essenciais na busca por novos conhecimentos.

Portanto, a infância é um período de muita importância para o ser humano, visto que nesse período acontece o desenvolvimento não só da personalidade, mas também do potencial criativo. As atividades propostas nos artigos aqui analisados nos indicam como é importante que a criança e seu conhecimento prévio sejam o ponto de partida das atividades planejadas em sala de aula. Assim o seu potencial integrador pode ser alcançado, possibilitando a construção e a ampliação de seus conhecimentos por meio de atividades lúdicas e significativas.

Para Piaget (1976, p. 73):

Os fundamentos para o desenvolvimento matemático das crianças estabelecem-se nos primeiros anos. A aprendizagem matemática constrói-se através da curiosidade e do entusiasmo das crianças e cresce naturalmente a partir das suas experiências [...] A vivência de experiências matemáticas adequadas desafia as crianças a explorarem ideias relacionadas com padrões, formas, número e espaço duma forma cada vez mais sofisticada.

Dessa forma, concordamos com os autores dos artigos analisados ao defenderem que o Ensino da Matemática é de fundamental importância para o desenvolvimento integral das capacidades, competências e habilidades do ser humano. O caso da Educação Infantil é particular e específico e o professor precisa ser visto como o 
"possibilitador" de formação da criança, ou seja, como alguém que auxilia na formação tanto para a vida quanto para o aprimoramento do raciocínio lógico e da criatividade.

\title{
3.2 A LUDICIDADE E O ENSINO DA MATEMÁTICA
}

A matemática é uma área do conhecimento considerada, via senso comum, como incompreensível, complicada e de difícil entendimento. Portanto, ensinar conceitos matemáticos de forma lúdica torna-se importante para diminuir os preconceitos e para contribuir para a compreensão ao longo de toda a vida escolar.

A ludicidade é uma ação pedagógica que está propriamente ligada à criança, possibilitando que ela construa novos conhecimentos, podendo ser expressada de diversas formas, ou seja, por meio de jogos, danças, brincadeiras e brinquedos, sendo que estes estão constantemente presentes no dia a dia fora da escola e no cotidiano da Educação Infantil.

Nesse sentido, Almeida (2003, p. 14) afirma que

\begin{abstract}
Educar ludicamente tem um significado muito profundo e está presente em todos os segmentos da vida. Por exemplo, uma criança que joga bolinha de gude ou brinca de boneca com seus companheiros não está simplesmente brincando e se divertindo; está desenvolvendo e operando inúmeras funções cognitivas e sociais [...] Eles educam-se ludicamente, pois combinam e integram a mobilização das relações funcionais ao prazer de interiorizar o conhecimento e a expressão de felicidade que se manifesta na interação com os seus semelhantes.
\end{abstract}

Porém, é comum que pais e professores considerem que essas atividades não trazem nenhuma produtividade e não preparam a criança para a vida em sociedade. Nesse sentido, Piaget (1993, p. 25) defende que "o jogo não pode ser visto apenas como divertimento ou brincadeira para gastar energia, pois ele favorece o desenvolvimento físico, cognitivo, afetivo e moral". Portanto, a brincadeira, quando fundamentada e orientada de modo significativo, permite o desenvolvimento infantil integral, pois proporciona diferentes tipos de atividades, ampliando a construção de conhecimentos e vínculos entre professor e criança e entre elas.

Para Froebel (1912 apud KISHIMOTO, 1996), a brincadeira é fundamental, primordialmente nos primeiros anos de vida.

\footnotetext{
Neste estágio de desenvolvimento a criança vai crescendo como ser humano que sabe usar seu corpo, seus sentidos, seus membros. Meramente por motivo de seu uso ou prática, mas não por busca de resultados em seu uso. Ela é totalmente indiferente a isso, ou melhor, ela não tem ideia sobre o significado disso. Por tal razão a criança neste estágio começa a brincar com seus membros - mãos, dedos, lábios, línguas, pés, bem como com as expressões dos olhos e face. (FROEBEL 1912, p. 48 apud KISHIMOTO, 1996, p.157).
} 
Por meio da brincadeira, a criança tem um modo privilegiado de se autodesenvolver, além da disposição de construir seus conhecimentos. Através da ludicidade, pode-se proporcionar a aquisição e a aceitação de regras, momentos de interação com os outros, além de oportunidades para se expressar.

Quando abordamos a ludicidade, a brincadeira e as interações, ponderamos a importância pedagógica do lúdico na Educação Infantil. Nesta etapa da escolarização, a brincadeira é um instrumento facilitador da aprendizagem, pois o brincar é visto como uma fonte prazerosa de interação com o mundo e de novas descobertas. Logo, no momento em que a criança é atraída pela brincadeira e pela fantasia, libera sua imaginação e experimenta novas habilidades, explorando todo o seu potencial.

Dessa forma, no artigo 1, percebemos que a ludicidade está presente durante a atividade proposta, pois já no início cria-se um momento de suspense e incentiva-se que as crianças imaginem os animais que seriam possíveis e impossíveis de serem encontrados em uma visita ao bosque. Além disso, o ambiente escolhido (bosque) atrai a atenção e o interesse, possibilitando que elas dialoguem e argumentem sobre o que já conhecem sobre o assunto. É o que podemos observar no relato:

\begin{abstract}
A proposta foi realizada de modo integrado ao que já estava previsto no trabalho com a turma. Foi apresentada às crianças uma questão relacionada ao "passeio" que seria realizado na semana seguinte, a visita ao bosque. Inicialmente, foi perguntado à turma: quais animais possivelmente encontraremos no bosque? e quais animais seriam impossíveis de serem encontrados? [...] Para ouvi-los, foi organizada uma roda e a professora atuou como escriba anotando num cartaz, com caneta azul os animais que as crianças acreditavam que era possível encontrar e com caneta vermelha os animais que as crianças achavam impossível encontrar. Essa atividade favoreceu a reflexão sobre a escrita com as crianças. (ALMEIDA; FERNANDES; MEGID, 2017, p. 100. Artigo 1).
\end{abstract}

Diante do exposto, percebemos que é pela brincadeira que a criança é introduzida no meio sociocultural do adulto, constituindo-se num modo de assimilação e recriação da realidade. Por meio das atividades lúdicas, a criança comunica-se consigo mesma e com o mundo, aceita a existência dos outros, estabelece relações sociais, constrói conhecimentos, desenvolvendo-se integralmente. Segundo o Referencial Curricular Nacional para a Educação Infantil (RCNEI) (1998, p. 22):

Brincar é uma das atividades fundamentais para o desenvolvimento da identidade e da autonomia. $\mathrm{O}$ fato de a criança, desde muito cedo, poder se comunicar por meio de gestos, sons e mais tarde representar determinado papel na brincadeira faz com que ela desenvolva sua imaginação. Nas brincadeiras as crianças podem desenvolver algumas capacidades importantes, tais como a atenção, a imitação, a memória, a imaginação. Amadurecem também algumas capacidades de socialização, por meio da interação e da utilização e experimentação de regras e papéis sociais. 
A atividade de circuito, apresentada no artigo 2, e a atividade de exploração, apresentada no artigo 4, objetivam a construção de conceitos elementares de orientação espacial, buscando atender às especificidades da faixa etária, como podemos constatar nos frames a seguir:

As ideias geométricas referentes ao senso espacial estão presentes em diversas situações da vida. Nós as utilizamos diariamente quando precisamos ler um texto, olhar as horas, encontrar um endereço, medir uma roupa, fazer uma caminhada, desenhar, seguir as orientações do GPS etc. (ZOGAIB; SANTOS-WAGNER, 2017, p. 52. Artigo 2).

A atividade toda durou cerca de 30 minutos, tempo consideravelmente bom para crianças dessa faixa etária, uma vez que é comum que haja desinteresse pelas atividades propostas após cerca de 10 minutos. Os materiais explorados na atividade são simples, mas que provocam nas crianças dessa faixa etária o desejo pela exploração de diferentes maneiras de composição: bolas, caixas, crianças dentro de caixas, bolas e crianças juntas em caixas, etc. Nessa exploração, as noções de espaço vão sendo construídas e a problematização do professor, no sentido de provocá-los a pensar sobre objetos, posições e quantidades, coloca o pensamento matemático da criança em movimento. (PELLATIERI, 2010, p. 32. Artigo 4).

Ao usufruir da ludicidade como recurso didático-pedagógico, as professoras possibilitaram que as crianças, ao brincarem, pudessem se expressar mostrando os seus conhecimentos e testando hipóteses para buscar responder as problematizações trazidas pelas mediações estabelecidas. Logo, o lúdico é um recurso eficaz, introduzir no espaço educacional atividades que contribuam para a construção do conhecimento e que favoreçam a formação da criança, tornando-a apta para lidar com desafios e intervir na realidade.

No artigo 3, as professoras que realizaram a atividade demonstraram consciência da importância da ludicidade nas ações pedagógicas. São apresentadas no texto reflexões sobre o tema, destacando-se a importância do trabalho com a matemática de forma prazerosa, favorecendo a aquisição de conceitos. Dessa forma, concordamos com as autoras quando defendem que:

A educação infantil é um espaço privilegiado para a aquisição de noções básicas de conceitos matemáticos. O ensino dessa disciplina deve ter a finalidade de construir um saber que possibilite às crianças pensar e refletir sobre o seu cotidiano, por meio de experiências vivenciadas. Isso será possível se elas tiverem contato, cada vez mais, cedo com propostas lúdicas, as quais possibilitam a ampliação de seus conhecimentos. (CARNIEL et al., 2016, p. 43. Artigo 3).

Foram utilizadas estratégias como a brincadeira, contações de histórias, jogos, fabricação de tintas, manuseio de materiais, livros de receitas, interligando diversas 
áreas de conhecimento e possibilitando a articulação dos conhecimentos matemáticos com sua utilidade prática. De acordo com Kishimoto (1996, p.183):

Brincar é uma atividade cotidiana na vida das crianças. O brinquedo é a essência da infância e sua principal atividade. A brincadeira com o brinquedo é a forma pela qual ela resolve a maioria dos conflitos criados pelas limitações do mundo em que vive e que é, eminentemente, um mundo dos adultos. Através da brincadeira a criança expressa sua forma de representação da realidade.

Portanto, o brincar tem uma função essencial na Educação Infantil, principalmente no tocante à construção de conhecimentos e ao desenvolvimento da criança, especialmente nos primeiros cinco anos de vida. Nesse período, geralmente, executam-se tarefas que são fundamentais, voltadas à ampliação da linguagem matemática, da imaginação, da exploração, da investigação, além da construção da função simbólica. Contudo, a finalidade da atividade lúdica na Educação Infantil é simplificar a aprendizagem para a criança, sendo que o ambiente necessita estimulá-las e respeitá-las, recordando que sujeito tem o seu tempo para aprender.

\subsection{PRÁTICAS PEDAGÓGICAS E O ENSINO DA MATEMÁTICA}

O Ensino da Matemática na Educação Infantil pode ter como base diferentes metodologias, nas quais a criança pode ser ou não o foco do planejamento das atividades, sendo que essa "flexibilidade" pode influenciar a maneira como ela incorporará a matemática em sua vida.

Nesse sentido, para que a experiência com a matemática seja significativa e agradável para as crianças, é necessário que o professor leve em consideração que a matemática se faz presente no cotidiano desde seus primeiros anos de vida, uma vez que os números estão em objetos (calendário, relógios, celulares), jogos, músicas e brincadeiras. Dessa forma, quando entram na Educação Infantil, trazem consigo um conhecimento prévio.

Nesse sentido, de acordo com Lorenzato (2006), o professor tem um papel fundamental no sucesso ou fracasso escolar. Para este autor, não é suficiente o professor dispor de um bom material didático para que se tenha efetivamente uma aprendizagem significativa. Mais relevante do que isso é saber utilizar corretamente esses materiais em sala de aula, articulando-os com os conhecimentos prévios das crianças. 
Além disso, é importante que o professor também esteja atento para que as atividades envolvendo a matemática ultrapassem o ensino dos números. De acordo com o Referencial Curricular Nacional para a Educação Infantil (1998), deve-se abranger os números e sistema de numeração, grandezas e medidas, além de espaço e forma. Ainda em relação ao Ensino da Matemática, o documento aponta que:

O trabalho com noções matemáticas na educação infantil atende, por um lado, às necessidades das próprias crianças de construírem conhecimentos que incidam nos mais variados domínios do pensamento; por outro, corresponde a uma necessidade social de instrumentalizá-las melhor para viver, participar e compreender um mundo que exige diferentes conhecimentos e habilidades. (BRASIL, 1998, p. 207).

Além de sinalizar os conteúdos a serem trabalhados no decorrer da Educação Infantil, o RCNEI indica que o trabalho com a matemática nesta faixa etária necessita ter a finalidade de oportunizar o desenvolvimento das seguintes capacidades:

Crianças de zero a três anos: estabelecer aproximações a algumas noções matemáticas presentes no seu cotidiano, como contagem, relações espaciais etc.

Crianças de quatro a seis anos: Para esta fase, o objetivo é aprofundar e ampliar o trabalho para a faixa etária de zero a três, garantindo, ainda, oportunidades para que sejam capazes de: reconhecer e valorizar os números, as operações numéricas, as contagens orais e as noções espaciais como ferramentas necessárias no seu cotidiano; comunicar ideias matemáticas, hipóteses, processos utilizados e resultados encontrados em situaçõesproblema relativas a quantidades, espaço físico e medida, utilizando a linguagem oral e a linguagem matemática; ter confiança em suas próprias estratégias e na sua capacidade para lidar com situações matemáticas novas, utilizando seus conhecimentos prévios. (BRASIL, 1998, p. 215).

Assim, é possível potencializar as aprendizagens que favoreçam o desenvolvimento do pensamento, o controle das ações sensoriais, as formações cognitivas e intelectuais, considerando a criança como sujeito histórico, social e cultural. Dessa maneira, possibilita-se a formação de crianças como cidadãs autônomas, produtoras de conhecimento e cultura, crítico-reflexivas, solidárias e atuantes em sua realidade, inclusive nas transformações para o seu bem-estar, para a aquisição de diversos saberes, habilidades e competências. Neste sentido, ao percebermos a importância da prática pedagógica do Ensino da Matemática na Educação Infantil, emergiu a terceira categoria de análise, "Prática Pedagógicas".

Durante a análise do artigo 1, é notável que a prática pedagógica adotada pela professora coloca a criança em foco, considerando seus conhecimentos prévios, possibilitando que se expresse e explore os materiais, colocando-a como sujeito ativo durante as atividades desenvolvidas. $O$ trabalho é realizado de uma forma 
interdisciplinar, utilizando diferentes recursos, como a escrita, o desenho, gráficos, tabelas e imagens, como podemos observar no frame a seguir:

\begin{abstract}
Após esse momento de exploração inicial das informações obtidas através da lista e da escolha do animal preferido, foi observado que várias crianças, ao serem questionadas sobre os animais "que não gostaram muito" mencionaram os animais com um voto, realizando uma interpretação inicial das ideias apresentadas nesta primeira forma de representação. No dia seguinte, a professora trouxe para a sala um cartaz com ilustrações dos animais que obtiveram algum voto. Depois de um momento de conversa para retomar a lista sobre os animais do bosque e a votação do dia anterior, a professora entregou a cada criança um pedaço de papel vermelho (um voto) e solicitou que colassem no cartaz, representando o voto acima do desenho de seu animal favorito. Dessa maneira, retomou o cartaz inicial e realizou outra forma de representação. (ALMEIDA; FERNANDES; MEGID, 2017, p. 102. Artigo 1).
\end{abstract}

Nesse sentido, contrapondo-se ao paradigma do exercício, Skovsmose (2008)

defende um ambiente de ensino favorável à investigação, chamando de Cenário para

Investigação as ações que dão suporte ao trabalho investigativo, convidando os alunos a

formularem questões e a procurarem explicações.

Um cenário para investigação é aquele que convida os alunos a formular questões e a procurar explicações. O convite é simbolizado por seus "Sim, o que acontece se...?". Dessa forma os alunos se envolvem no processo de exploração e explicação. O "Por que isto?" do professor representa um desafio, e os "Sim, por que isto...? dos alunos indicam que eles estão encarando o desafio e estão em busca de explicações, o cenário de investigação passa a constituir um novo ambiente de aprendizagem. No cenário de investigação os alunos são responsáveis pelo processo. (SKOVSMOSE, 2007, p. 21).

Da mesma forma, observamos que as autoras Almeida, Fernandes e Megid (2017) destacam a importância de situações-problema que estimulem a autoconfiança. O professor desempenha o papel do outro na interação da criança, construindo, com ela, diversas formas de cultura, interação, diálogo e comunicação diversificada, constituindo seu jeito de ser, sua subjetividade, gostos, entre outros. As autoras destacam:

Consideramos relevante que os adultos aproveitem tais momentos com as crianças para dialogar, procurar compreender o que já vivenciaram, como expressam e pensam a respeito do que fazem. Essas conversas precisam ocorrer em diferentes ocasiões para que possam ir construindo, reconstruindo e internalizando suas aprendizagens com as outras crianças e com adultos. Evidenciamos, aqui, essa necessidade em relação à atividade de circuito. Ficamos com uma série de perguntas que poderiam ser feitas às crianças: De onde veio a ideia de Matheus de que direita corresponde à mão que eu escrevo e esquerda ao lado do coração? Não havia na sala alguma criança que utilizava a mão esquerda para escrever? Como ficaria esse conceito, então? Que outros conceitos poderiam ser construídos a partir desse questionamento e outros que surgissem ou que fizéssemos? (ZOGAIB; SANTOS-WAGNER, 2017, p. 58. Artigo 2). 
A análise do artigo 2 forneceu indícios para nossa reflexão, dos quais destacamos: (a) a atividade de circuito indicou que as crianças possuem conhecimentos relacionados à orientação espacial que poderiam ser explorados pelas professoras, para posteriormente serem ampliados; (b) as atividades realizadas precisariam ser reestruturadas para um efetivo trabalho pedagógico; e (c) há a necessidade de o planejamento inicial ser repensado e adequado às respostas das crianças naquele tempo e espaço.

Portanto, o papel do professor precisa ser o de mediador, colaborando naquilo que a criança não consegue realizar sozinha e naquilo que ela consegue ir aperfeiçoando, por exemplo, ensinando a manusear um brinquedo, explicando os instrumentos disponíveis, desafiando sua própria autonomia, através da exploração do espaço, do movimento e do conhecimento do próprio corpo como um elemento de constituição da subjetividade.

A atividade descrita no artigo 3 permitiu explorar vários conceitos que a criança precisa adquirir nessa fase, como cores, formas, tamanhos, texturas, quantidades, diferenças e semelhanças, entre outros. Percebe-se que, ao elaborar a atividade, houve uma preocupação, por parte das professoras envolvidas, em se trabalhar com esses conceitos, que se fazem presentes no cotidiano.

\begin{abstract}
Através do uso de jogos como quebra-cabeça, dominó e memória com imagens de frutas e legumes, as crianças desenvolvem a linguagem oral e o raciocínio lógico, fazendo comparações, além do rico momento de estarem interagindo em pequenos e grandes grupos. [...] Além de servir para nos alimentar, descobrimos que alguns alimentos servem de tintas e com elas podemos criar o que quisermos. Fizemos tintas de beterraba, cenoura, couve, urucum, repolho roxo e outros. A fração faz parte do nosso dia a dia e temos que demonstrar isso de forma prática para que o entendimento seja fácil. Dividindo as frutas em partes, a criança acompanha e conta; desse modo, percebe que podemos dividir uma fruta em quantos pedaços quiser. (CARNIEL et al., 2016, p. 45. Artigo 3).
\end{abstract}

As propostas pedagógicas envolvendo a matemática se fizeram presentes no dia a dia da turma, de maneira que chegaram até mesmo a alterar os interesses coletivos dos alunos, os quais passaram a preferir brincar com jogos, como relatam as professoras: “por meio dos jogos, obtivemos mudança de interesse no grupo que antes demonstrava interesse por brincadeiras livres e hoje preferem trabalhar o raciocínio através dos jogos." (CARNIEL et al., 2016, p. 46. Artigo 3). Pode-se perceber que o trabalho com os jogos possibilita para as crianças uma aprendizagem significativa de conceitos e conteúdos matemáticos, desenvolvendo o raciocínio lógico e capacidades como as de 
observar, questionar, analisar, explorar, criar hipóteses, refletir e inferir sobre o que aprende.

No artigo 4, a prática pedagógica adotada pela professora durante a atividade relatada coloca as crianças em foco, possibilitando que se expressem, manipulem e explorem os materiais.

Primeiro contei uma breve história de uma menina que tinha uma lata comprida cheia de bolas pequenas, uma lata baixa cheia de bolas médias e uma caixa grande cheia de bolas grandes. Depois apresentei às crianças o material; montei os recipientes com as quantidades de bolas que cabiam em cada um, junto com as crianças e as convidei para brincar com as bolas, como a menina da história. Em seguida, cada criança escolheu a latinha que queria. $\mathrm{O}$ terceiro momento ficou livre para que as crianças explorassem os materiais. (PELLATIERI, 2010, p. 28. Artigo 4).

Fica evidente no frame acima que, durante a atividade, houve a preocupação da professora em preparar o ambiente, criando um Cenário para Investigação, conforme definição de Skovsmose (2008). Isso se deu através da contação da história, possibilitando que as crianças utilizassem o espaço da sala para explorar os materiais e interagir com seus colegas.

Ao finalizarmos a análise dos artigos selecionados, percebemos que as propostas pedagógicas envolvendo a matemática podem estar presentes nas turmas com crianças pequenas, propiciando o contato com situações-problema, através da exploração de objetos, brincadeiras e atividades lúdicas, sempre com a mediação da professora. Esta precisa estimular as crianças a resolverem as situações-problema criadas através de sua intervenção, trabalhando com os conteúdos matemáticos a partir da exploração do material e das problematizações.

Segundo Fiorentini (1995), a aquisição do conhecimento ocorre quando o aluno estabelece relações entre o seu conhecimento prévio do tema e os novos saberes. Além disso, a matemática oferece ao professor diversas oportunidades de desafiar seus alunos a encontrarem soluções para as questões que enfrentam na vida diária.

$\mathrm{Na}$ realização da pesquisa que deu origem a este trabalho, percebemos, inicialmente, a escassez de publicações na área do ensino de matemática na Educação Infantil. Além disso, entendemos que, por ser esse um tema de extrema importância, precisa ser abordado por pesquisadores e estudiosos, tanto em cursos de formação inicial (graduação em pedagogia e matemática) e continuada, quanto em artigos, teses, livros etc. 
$\mathrm{Na}$ análise dos artigos, encontramos exemplos de atividades que partiram do saber das crianças de zero a seis anos e que trouxeram aprendizado matemático a partir de atividades práticas possíveis de serem realizadas em seu contexto. A diversidade de situações de aprendizagem que encontramos evidenciam as possibilidades de se promover o desenvolvimento do potencial integrador das crianças da Educação Infantil. Além disso, a realização de atividades lúdicas nas instituições proporciona o desenvolvimento de aspectos cognitivos, elevando a autoestima e tornando as crianças sujeitos ativos, críticos e mais preparados para resolver problemas de seu cotidiano, culminando em uma aprendizagem significativa.

\section{CONSIDERAÇÕES FINAIS}

O presente artigo teve como objetivo analisar algumas atividades matemáticas lúdicas como recursos pedagógicos para o contexto da Educação Infantil, com base na abordagem piagetiana e nos pressupostos da Educação Matemática. Ao longo deste texto, buscamos evidenciar a importância das experiências nessa faixa etária e que a relação entre o Ensino da Matemática e a ludicidade favorece o interesse e o aprendizado da criança, tornando-o mais prazeroso e menos complicado.

A análise nos forneceu subsídios para a compreensão de que a construção do conhecimento ocorre por meio da interação do sujeito com a realidade, o que nos levou a entender que uma alternativa metodológica coesa com a concepção piagetiana se manifesta por meio da resolução de problemas. A Educação Infantil, dessa forma, tornase um espaço para as crianças realizarem investigações e analisarem seus resultados, possibilitando o registro de maneira a propiciar-lhes o desenvolvimento do pensamento matemático.

Desse modo, as atividades lúdicas podem se tornar um auxílio pedagógico quando bem planejadas, organizadas e orientadas pelos professores, visando e proporcionando às crianças a aquisição de aprendizagem da matemática. Ao trabalhar os conceitos e conteúdos relacionados ao sistema de numeração, geometria e através da resolução de problemas matemáticos, a criança desenvolve a capacidade de observar, questionar, analisar, explorar, criar hipóteses, refletir e inferir sobre o que ela aprende. 
Consideramos, ainda, que o Ensino da Matemática na Educação Infantil necessita oferecer situações significativas de aprendizagem, relacionando a matemática às demais linguagens, como os exemplos apontados nos artigos analisados neste texto. Dessa forma, destacamos a importância do trabalho com diferentes práticas pedagógicas nas quais o lúdico está presente, pois tem a possibilidade de tornar o aprendizado mais prazeroso, auxiliando na compreensão dos conteúdos, além de permitir o desenvolvimento de habilidades motoras e cognitivas.

Ademais, acreditamos que seja necessária uma conscientização por parte dos professores sobre a real possibilidade de se trabalhar o Ensino da Matemática na Educação Infantil. Aliado a essa conscientização, acreditamos que é preciso, também, reconhecer a necessidade de valorização dos saberes prévios das crianças pois, do contrário, corre-se o risco de uma mera "simplificação" e "despejo" de conteúdos que, no fim das contas, não resultam em um conhecimento significativo.

\section{REFERÊNCIAS}

ALMEIDA, A. R. de; FERNANDES, K. L. da S.; MEGID, M. A. B. A. Vamos ao bosque? Problematizações e tratamento da informação na Educação Infantil. Educação Matemática em Revista, v. 22, n. 54, p.98-105, abr/jun 2017.

ALMEIDA, P. N. Educação lúdica: Técnicas em jogos pedagógicos. São Paulo: Loyola, 2003.

BRASIL. Ministério da Educação e do Desporto, Secretaria de Educação Fundamental. Referencial Curricular Nacional para a Educação Infantil. Brasília: MEC/SEF, 1998. 3v.: il.

BRASIL. Resolução CNE/CEB 5/2009. Diário Oficial da União, Brasília, 18 de dezembro de 2009, Seção 1, p. 18. Disponível em:

<http://www.seduc.ro.gov.br/portal/legislacao/RESCNE005_2009.pdf $>$. Acesso em: Set. 2017.

CARNIEL, A. L.; RENKEN, A.; SCHNEIDER, S. V.; FORTUNATO, V. Educação Infantil e a Matemática na Alimentação Saudável. Educação Matemática em Revista, v. 50, p. 26-34, maio 2016.

CARVALHO, A. M. P. et al. Ciências no ensino fundamental: o conhecimento físico. São Paulo: Scipione, 2007. 
FIORENTINI, D. Alguns Modos de Ver e Conhecer o Ensino da Matemática no Brasil. Zetetiké, Campinas, n. 4, p. 1-37, 1995.

GOULART, I. B. Piaget: experiências básicas para utilização pelo professor.

Petrópolis: Vozes, 1996.

KISHIMOTO, T. M. Froebel e a concepção de jogo infantil. Revista da Faculdade de Educação, São Paulo, 1996.

LORENZATO, S. Laboratório de ensino de matemática e materiais didáticos manipuláveis. Campinas: Editores Associados, 2006.

MINAYO, M. C. S. (Org.). Pesquisa Social: Teoria, método e criatividade. 23.ed, Petrópolis: Vozes, 2004.

PELlAtieri, M. Qual Matemática Para Crianças Tão Pequenas? Explorando As Noções de Espaço Com Crianças de 1 a 3 Anos. Educação Matemática em Revista, v. 29, p. 43-47, mar. 2010.

PIAGET, J. A construção do real na criança. Rio de Janeiro: Zahar, 1970.

PIAGET, J. A Epistemologia Genética. 2 ed. Petrópolis: Vozes 1973.

PIAGET, J. Psicologia e Pedagogia. Rio de Janeiro: Forense Universitária, 1976.

PIAGET, J. A Linguagem e o Pensamento da Criança. 6. ed. São Paulo: Martins Fontes, 1993.

SKOVSMOSE, O. Educação crítica: incerteza, matemática e responsabilidade. Tradução de Maria Aparecida Viggiani Bicudo. São Paulo: Cortez, 2007.

SKOVSMOSE, O. Desafios da Reflexão em Educação Matemática Crítica. Campinas: Papirus, 2008.

SMOLE, K. A matemática na educação infantil: a teoria das inteligências múltiplas na prática escolar. Porto Alegre: Artes Médicas, 2000.

ZOGAIB, S. D.; SANTOS-WAGNER, V. M. P. dos. Entre caixas, bolas e bambolês: a orientação espacial na educação infantil. Educação Matemática em Revista, v. 53, p. 51-61, 2017. 